\title{
O CORPO NO ESPAÇO E COMO ESPAÇO: MAPEAMENTOS PARA SE PENSAR A INCLUSÃO
}

Renato de Sena Vieira ${ }^{\mathrm{i}}$

Resumo: Pretende-se, neste trabalho, sinalizar as relações estabelecidas com o espaço dentro das atividades de dança realizadas com pessoas que estão dentro do Transtorno do Espectro Autista num Centro Municipal de Referência da Pessoa com Deficiência, localizado no Rio de Janeiro. Discute-se, aqui, o espaço desses corpos dentro dos vários ambientes escolares, entendendo o autismo como uma forma diferente de ver o mundo e de estar no mundo. Ambiciona-se que crianças e jovens percebam a escola como um território que promova o encontro com a experiência, algo essencial para a inclusão desses estudantes.

Palavras-chave: Corpo; Transtorno do Espectro Autista; Educação.

Resumen: En este trabajo, se pretende señalar las relaciones establecidas con el espacio dentro de las actividades de danza realizadas con personas que están dentro del trastorno del espectro autista en un Centro Municipal de Referencia de Personas con Discapacidades, ubicado en Río de Janeiro. Aquí se discute el espacio de los cuerpos dentro de los varios ambientes escolares, percibiendo el autismo como una forma diferente de ver el mundo y de estar en el mundo, donde los niños y jóvenes pueden ver a la escuela como un territorio que promueve la reunión con la experiencia, imprescindible para la inclusión de estos estudiantes.

Palabras clave: Cuerpo; Trastorno del espectro autista; Educación.

Summary: In this de work, I seek signal relations that I have established with space within may dance activities performed in the Municipal Center of Reference of the Person with Disabilities, in Rio de Janeiro, with people who are within autistic spectrum disorder. I seek, then, to bring to the discussion the space of these bodies within the various places existing in the school, perceiving autism as a different form to see the world and be in the world, where children and young people can see in the school a territory that promotes the encounter experience, something essential for the inclusion of these students.

Keywords: Body; Autistic Specutrum Disorder; Education.

\section{Introdução}

A palavra espaço assume inúmeras possibilidades que dão a esse termo uma imensa plasticidade, pluralizando-o e desdobrando-o em múltiplos territórios a serem Commons Atribuição Não Comercial-Compartilha Igual (CC BY-NC-4.0), que permite uso, distribuição e reprodução para fins não comerciais, com a citação dos autores e da fonte original e sob a mesma licença. 
vivenciados. No ambiente escolar, pode-se falar sobre os espaços físico, público, privado, criativo, de aprendizagem, vago, mental, corporal, de uma folha em branco etc.

O homem sempre mostrou interesse em descobrir o seu espaço, bem como dominá-lo, explorá-lo e conquistar outros. Essa condição quase natural da humanidade traz reflexos na educação, que, ao longo da história, buscou centralizar o tempo e o espaço do corpo, promovendo a ordem e a hierarquia — os ambientes escolares e suas próprias disposições internas dizem onde há ou não a possibilidade do movimento.

Dentro da construção do ensino brasileiro, que possui, em sua raiz, uma estruturação que visa ao controle, tem-se a incorporação de agentes, como a figura do professor e do coordenador, a estrutura seriada, as avaliações, a utilização de cadeiras enfileiradas e o conteúdo ensinado. Todos esses indicadores funcionam como mecanismos de poder e obediência na busca de controle do espaço da infância.

Segundo Fraga (2006, p. 65):

$\mathrm{Na}$ época atual, todas essas instituições - fábrica, escola, hospital psiquiátrico, hospital, prisão - têm por finalidade não excluir, mas, ao contrário, fixar os indivíduos. A fábrica não exclui os indivíduos; liga-os a um aparelho de produção. A escola não exclui os indivíduos; mesmo fechando-os, ela os fixa a um aparelho de transmissão do saber. O hospital psiquiátrico não exclui os indivíduos; liga-os a um aparelho de correção, a um aparelho de normalização dos indivíduos. Isso ocorre com a casa de correção ou com a prisão.

Essa fixação como forma de padronizar sujeitos, apontada por esse autor, possibilita a reflexão sobre a construção de corpos, que, desde a primeira infância, vão sendo aprisionados por esferas de poder em correntes invisíveis. Isso acaba por criar sujeitos sem intimidade com seus próprios corpos, com dificuldades de interação social, sujeitos que não respeitam aquele que seria a sua primeira casa, a que você tem desde que nasceu, muito antes de morar em qualquer outro lugar, é seu corpo (VIANNA; CASTILHO, 2002, p.18)

Quando falamos sobre o corpo dentro do ambiente escolar, devemos ampliar nossa percepção para além de ambientes físicos específicos (como o pátio e a quadra de esportes) ou de disciplinas direcionadas, enxergando-o como território de criação, como um espaço a ser apropriado e construído por cada um que o frequente. Passo, então, a 
perceber cada pessoa como um dançarino, mesmo antes de sê-lo, entendendo que o movimento é algo necessário à própria sobrevivência e à vida.

Pensar o movimento como parte essencial na travessia dos diferentes territórios existentes em todas as Fases da Vida (BERTAZZO, 2018) é um desafio a ser superado não apenas dentro da escola. Compreender que o espaço e o tempo, nesse ambiente, são ativos é fundamental para estruturar o núcleo psicoafetivo dos sujeitos.

Para Lapierre e Aucouturier (1986, p. 69):

É nesse nível, atualizado no presente, que deve situar-se inicialmente toda ação educativa "reeducativa" ou terapêutica. Quando uma criança conserva ou reencontra seu equilíbrio psicoafetivo, sua alegria de viver, seu dinamismo, seu desejo de afirmação, seu desejo de expressão e comunicação, sua criatividade, sua curiosidade, as "aprendizagens escolares" não apresentam mais problemas, sejam quais forem os métodos empregados.

Com base nisso, reforça-se que devemos despertar, como educadores, o desejo de agir e de ser a partir do movimento, fazendo, assim, com que os alunos se tornem sujeitos autônomos nos seus processos de autoconhecimento e de aprendizagem. Isto só é possível se proporcionarmos espaços para tal, de modo que a criança possa se expressar sem medo, inibição ou agressividade, sem se esconder em estereótipos ou normas. Uma escola precisa ser feita de espaços inclusivos, plurais e afetivos.

Esse espaço escolar universal e unificado deve abrigar todos os corpos, especialmente os invisíveis e inferiorizados pela nossa história. Refiro-me, aqui, aos corpos que foram punidos ao longo da sua existência, que foram - e são! - jogados em espaços marginais; corpos que a sociedade finge não ver, corpos atípicos, fora dos padrões da normatividade, defeituosos, que são discriminados, precarizados e rotulados. Destes, tenho me aproximado como professor de dança em um Centro Municipal de Referência para pessoas com deficiências, desde o ano de 2017. 


\section{A chegada do corpo atípico no território escolar}

A história nos conta que o processo de inclusão tem sido um percurso árduo, marcado pela aceitação e pela luta de familiares e de pessoas com deficiência por reconhecimento e políticas de direito. Esses indivíduos vêm, ao longo da história, buscando uma mudança do olhar da sociedade para a deficiência e para todas as especificidades. $\mathrm{O}$ acesso à educação nasceu de uma longa caminhada e, como veremos a seguir, essas pessoas têm ocupado, aos poucos, seu espaço de direito na escola regular.

A respeito da Lei e da educação no Brasil, foi apenas em 1961 que encontramos, na Lei de Diretrizes e Bases da Educação Nacional (LDB), Lei $\mathrm{n}^{\circ} 4.024 / 61$, um título direcionado às pessoas com deficiência — denominadas pelo documento como "excepcionais" - , que ressalta a integração desses estudantes no espaço escolar público e privado: Art. 88. A educação de excepcionais deve, no que for possível, enquadrar-se no sistema geral de educação, a fim de integrá-los na comunidade (BRASIL,1961).

Apenas com a Constituição Federal de 1988 é que se estabeleceu a educação como direito de todos. $\mathrm{O}$ art. 208 ressalta o atendimento educacional especializado aos portadores de deficiência, preferencialmente na rede regular de ensino (BRASIL, 1988). No que corresponde à Educação Básica obrigatória e gratuita dos 4 aos 17 anos, a Constituição deixa clara a obrigatoriedade do Estado em garantir o atendimento educacional especializado às pessoas com deficiência em salas regulares.

A Conferência Mundial de Necessidades Educativas Especiais: Acesso e Qualidade, realizada pela UNESCO (1994), em Salamanca, foi um marco — nesse momento, começou-se a olhar com maior problematização as causas da exclusão escolar, ressaltando a importância das escolas em acolher todas as crianças, independentemente de suas condições físicas, intelectuais, sociais, emocionais, linguísticas ou outras. Com a adoção de uma educação inclusiva, respeitando as necessidades de cada um, enfatizou-se a necessidade de uma abordagem centrada na criança, objetivando a garantia de uma escolarização bem-sucedida para todas as crianças (UNESCO, 1994, p. 8). Assim, destaca-se uma nova forma de pensar o currículo. O conteúdo da educação deveria ser voltado a padrões superiores e às 
necessidades dos indivíduos, com o objetivo de torná-los aptos a participar totalmente no desenvolvimento (idem, p. 9).

É na LDB, Lei $n^{\circ}$ 9.394/96, que encontramos uma seção inteira dedicada a Educação Especial. Pode-se destacar o Art. 58: Entende-se por educação especial, para os efeitos desta Lei, a modalidade de educação escolar, oferecida preferencialmente na rede regular de ensino, para educandos portadores de necessidades especiais (BRASIL, 1996).

A quarta meta do Plano Nacional de Educação - PNE (2014) - objetiva universalizar o espaço escolar, englobando todos aos estudantes de 4 anos a 17 anos com deficiência, transtornos globais do desenvolvimento e altas habilidades ou superdotação, preferencialmente, na rede regular de ensino, com garantia de um ensino inclusivo. Ao mesmo tempo em que o PNE representa um grande avanço, a falta de dados que garantam maior clareza do cenário - que demonstrem a quantidade dessas crianças e jovens existentes no Brasil e quantos permanecem fora da escola — ressalta o quanto ainda é vago o campo da pesquisa nessa área.

É preciso destacar, também, a Lei $n^{\circ} 13.146$, de 6 de julho de 2015, conhecida como Lei Brasileira de Inclusão da Pessoa com Deficiência (Estatuto da Pessoa com Deficiência), que representa um marco na legislação brasileira por trazer diversos aspectos que falam do direito à inclusão das pessoas com deficiência dentro da sociedade. No que corresponde à educação, no capítulo IV, a lei procura aborda o direito e o dever do acesso e promover a inclusão dessas crianças e jovens no espaço escolar em todos os níveis de ensino, entretanto, não deixa clara a importância desses alunos estarem insertos na rede regular. No Art. 27 (BRASIL, 2015), encontramos:

A educação constitui direito da pessoa com deficiência, assegurados sistema educacional inclusivo em todos os níveis e aprendizado ao longo de toda a vida, de forma a alcançar o máximo desenvolvimento possível de seus talentos e habilidades físicas, sensoriais, intelectuais e sociais, segundo suas características, interesses e necessidades de aprendizagem.

Quando lançamos um olhar para o Transtorno do Espectro Autista 2 (TEA), podemos perceber que a falta de conhecimento sobre o autismo e as poucas pesquisas na área afetam o diagnóstico, o tratamento e, também, a inclusão na 


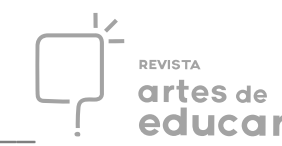

legislação. Os primeiros estudos que relatam o autismo foram apresentados somente em 1943, pelo doutor Leo Kanner (1894-1981) que, em carta para Mary Tripller — mãe da criança descrita por Kanner como Caso I - , afirmou: A principal distinção reside na incapacidade dessas crianças, desde a primeira infância, de se relacionar com as outras pessoas (DONVAN; ZUCKER, 2017, p. 50). Essa percepção ressalta as dificuldades de relacionamento e comunicação com a parte intelectual, destacando a incapacidade de estabelecer relações, o comportamento obsessivo e a preferência pelo isolamento, pela fuga da realidade.

Mesmo depois de anos da identificação do TEA, ainda não temos informações precisas que identifiquem a população dentro do Espectro. Segundo dados do CDC (Center of Deseases Controland Prevention), órgão ligado ao governo dos Estados Unidos, pesquisas mais recentes apontam que existe, hoje, um caso de autismo a cada 110 pessoas no mundo. Com essa estimativa, poderíamos dizer que o Brasil, com seus 200 milhões de habitantes, possui cerca de dois milhões de autistas.

A Lei $n^{\circ} 12.764$, que deu origem a Política Nacional de Proteção dos Direitos da Pessoa com Transtorno do Espectro Autista, foi sancionada em 27 de dezembro de 2012, pela presidenta Dilma Rousseff. A nova medida reconhece que os autistas possuem os mesmos direitos das pessoas com deficiência, garantindo-lhes a inserção em todas as políticas de inclusão existentes no país, entre elas, as de Educação.

Os últimos dados disponíveis do Senso Escolar relatam que o número de alunos com TEA que se encontram matriculados em classes comuns no Brasil aumentou 37,27\% em um ano. Em 2017, tínhamos 77.102 crianças e adolescentes com autismo estudando em classes regulares pelo país, mas esse índice subiu para 105.842 alunos em 2018.

O que percebemos, ao olhar as leis e os dados, é que mesmo depois de anos o TEA ainda é um estigma dentro da sociedade e isso se reflete nas leis que permeiam a educação. Le Breton (2007, p. 74) afirma que as relações vividas pelos deficientes em diferentes espaços, inclusive na escola, ainda estão no campo da aceitação — "Fala-se então de 'deficiente' como se em sua essência o homem fosse um 'ser' deficiente ao invés de 'ter' uma deficiência".

Fingimos que as alterações corporais, sensoriais e cognitivas não criam diferença e, de uma perspectiva da moral social, o corpo do sujeito deficiente deve passar 


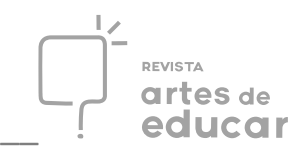

despercebido. Realizamos, durante toda a história, o que esse autor (idem) chamou “apagamento ritualizado do corpo" - e esquecemo-nos de olhar para esses sujeitos, de computar os dados de suas existências, de incluí-los na educação, nas leis, na sociedade.

Talvez o que não perceberíamos há anos é que o sujeito deficiente ganharia voz, ocupando os espaços que são seus por direito. Essas pessoas transgridem e interferem em interações já estabelecidas na regulação fluida existente pela ordem. O corpo da criança e do jovem deficiente provoca o desconhecido, tira a escola do seu lugar de conforto. Não adianta fingir que não os veem, pois seus corpos, só por existirem, se apresentam com evidência; só por estarem em um espaço, cobram transformações e exigem um ensino-aprendizagem fora das referências costumeiras. Esses corpos em movimento, que agora ocupam os espaços formais, não formais e informais, disputam um lugar com os outros.

Hoje, pelas leis, esses sujeitos são convocados para a inclusão, mas ainda brigam para vencer os processos excludentes. Dentro da escola, ainda imperam padrões, a ideia de uma ordem imposta, de um modo de ensinar e aprender, um aprisionamento do corpo. Este, como aponta Foucault (1987), está inserto em relações de poder que a todo tempo atuam sobre ele, direcionando sua forma de andar, sentar, correr, saltar, comer, dormir, vestir. Estamos, aqui, abordando as forças que atuam sobre os corpos com o intuito de transformá-los em força útil dentro da utilização econômica e social e que estão insertos, de forma enraizada, dentro da escola. Para esse autor (idem, p. 29) $o$ corpo só se torna força útil se é ao mesmo tempo corpo produtivo e corpo submisso.

Esses sujeitos com deficiência, que foram por tanto tempo silenciados, desafiam essas regras e demonstram no próprio corpo que precisam de outro espaço, diferente desse promovido pela sociedade, que é ordenado e reproduzido dentro da escola. Eles pedem por um espaço em que possam estar de forma autônoma, em que possam estabelecer relações, socializarem-se e se fazerem presentes e iguais em direito de ser, de agir, de sentir, de resistir.

\section{O corpo no espaço relacional}

Durante meu percurso dentro do Centro de Referência Municipal, atuando como educador de dança, pude perceber um aumento do público com TEA, representando 
cerca de $40,6 \%^{3}$ dos usuários atendidos em nossa unidade no ano de 2019 . De acordo com a American Psychiatric Association - APA (2014, p. 31):

O Transtorno do Espectro Autista caracteriza-se por déficits persistentes na comunicação social e na interação social em múltiplos contextos, incluindo déficits na reciprocidade social, em comportamentos não verbais de comunicação usados para interação social e em habilidades para desenvolver, manter e compreender relacionamentos.

Podem-se observar algumas dessas características do espectro nos discursos das famílias das crianças e jovens que frequentam o Centro de Referência. Ao realizarem seus apontamentos, ressaltam as dificuldades de concentração, de relacionamento e de comunicação, a agressividade (quando submetidos a situações de controle e disciplina), a restrição de ânimo para algumas atividades e outras áreas de interesse e a agitação e o descontrole físico e emocional quando expostos a determinados espaços.

Essas características que constituem o espectro são percebidas, muitas vezes, pelos pais e pela escola como bagunça, descontrole, falta de limites, desordem e falta de interesse, o que, em grande parte, está ligado à condição daquela criança em relação ao novo. Esses fatores são uma dificuldade dentro do espaço escolar, uma vez que sua obrigação não deve se resumir apenas em permitir a entrada do TEA na escola, mas também em passar pelo desafio de frequentarem as classes regulares de ensino.

Foucalt (1987, p. 169) afirma que:

O espaço disciplinar tende a se dividir em tantas parcelas quando corpos ou elementos há a repartir. É preciso anular os efeitos das repartições indecisas, o desaparecimento descontrolado dos indivíduos, sua circulação difusa, sua coagulação inutilizável e perigosa; tática de antideserção, de antivadiagem, de antiaglomeração. Importa estabelecer as presenças e as ausências, saber onde e como encontrar os indivíduos, instaurar as comunicações úteis, interromper as outras, poder a cada instante vigiar o comportamento de cada um, apreciá-lo, sancioná-lo, medir as qualidades ou os méritos. Procedimento, portanto, para conhecer, dominar e utilizar. A disciplina organiza um espaço analítico.

O que esse autor aponta é a forma pela qual as regras codificam o espaço escolar e como são essenciais para a estruturação da educação tradicional existente em nosso 
país. Nesse sentido, cada lugar do ambiente educacional é usado como uma forma de controle do corpo e do movimento, utilizando a localização espacial como uma forma de individualizar os corpos para dominar, realizando, então, uma forma espacial de controle hierárquico e funcional, que serve para individualizar e padronizar dentro de uma normalidade esperada. A chegada do TEA, então, que possui outro entendimento e necessidade espaço-temporal, causa estranheza, desconforto e, mais uma vez, a exclusão.

Devemos pensar que, na educação, temos vários mecanismos de controle que desejam a construção de um corpo padronizado para a sociedade — adulto, equilibrado, segmentado, distanciado e rígido, no qual a parte cognitiva reina como soberana em um corpo como espaço a ser colonizado.

O corpo que construímos, hoje, dentro da escola, é sem fronteiras, de um tempo acelerado e preenchido por milhares de informações. Fazemos isso junto com um currículo comum, que nos dá a ideia de um corpo universal que deve ser formado com um padrão único. Esquecemo-nos de olhar para os corpos dos alunos, inclusive os com deficiência, como pulsantes, que têm seu tempo, espaço e movimento individuais, enquanto buscam se articularem com as identidades sociais, com a cultura e com o currículo dentro da sala de aula.

Pensar nesse diálogo entre corpos como parte do currículo envolve desafios que passam por mudanças na forma pela qual concebemos e conhecemos a educação e o espaço escolar. Falar de um espaço dos corpos e de uma educação pelo e com o corpo é pensar em formas de romper controles e regras, buscando uma visão mais global do ser e mais relacional da educação. Segundo Lapierre e Lapierre (2002, p. 51): quando falamos de disponibilidade, é realmente disso que se trata: estar disponível ao desejo da criança e não lhe impor constantemente o nosso desejo.

O que esses autores nos apontam é a necessidade da escuta como a primeira forma para estabelecer um espaço em que possamos abraçar as diferentes formas de ser, de aprender, de brincar e de estar na escola. Este é também um território do não saber e da construção de experiências, por isso, deve-se romper com a imagem tradicional que temos do espaço educacional e criar novos locais que permitam que esses corpos falem pelo gesto, pela inquietude, pelo olhar.

Nesse cenário, Larrosa (2015, p. 25) salienta que: 


\begin{abstract}
A experiência, a possibilidade que algo nos aconteça, ou nos toque, requer um gesto de interrupção, um gesto que é quase impossível nos tempos que correm: requer parar, parar para pensar, parar para olhar, parar para escutar, pensar mais devagar, olhar mais devagar, e escutar mais devagar; parar para sentir, sentir mais devagar, demorar-se nos detalhes, suspender a opinião, suspender o juízo, suspender a vontade, suspender o automatismo da ação, cultivar a atenção e a delicadeza, abrir os olhos e os ouvidos, falar sobre o que nos acontece, aprender a lentidão, escutar os outros, cultivar a arte do encontro, calar muito, ter paciência e dar-se tempo e espaço.
\end{abstract}

Essa forma de pensar será essencial para que ocorra a acessibilidade do sujeito dentro do espectro autista, uma vez que sua própria condição demonstra a necessidade de construção de um tempo que nos escapa, desviando dos mecanismos de controle de tempo e espaço presentes na escola. Entendo que o espectro diz que nenhum sujeito com autismo é igual ao outro, pois há uma gama de condições que envolvem desde os níveis mais leves até os mais profundos das conexões de neurodesenvolvimento.

Entretanto, como particularidades tão distintas e singulares poderiam conviver no mesmo lugar, formando um espaço comum? Qual seria a importância de partilhar o mesmo território entre os alunos que são vistos como normais e aqueles que possuem deficiência?

Cabe lembrar as palavras de Viana (2015, p. 55):

Se o corpo se constrói na sua relação com o mundo, devo assim, nesse espaço de encontro - e antes mesmo de me pretender, de me convidar ao espaço do outro - ter consciência da minha própria Kinesfera, do que eu coloco como bolha de proteção de mim mesmo, das minhas partes mutiladas ou em construção.

Este apontamento que nos faz refletir sobre a importância de entender primeiro o nosso corpo e os nossos espaços, para depois podermos entrar em contato com o outro, é o começo dessas respostas. Tanto o autista como os ditos normais precisam entender suas dimensões corporais e compreender esse corpo como lugar de constante 
aprendizagem, de modo que haja relações a partir da geografia espacial, como relata esse autor.

O que percebo, atuando com a dança em espaço terapêutico, é que as pessoas com TEA percebem com mais clareza a nossa disponibilidade e indisponibilidade, uma vez que são mais sensíveis a tudo que nos transpassa e ao mundo. Desenvolver qualquer trabalho com sujeitos nesse espectro exige o que Viana (2015) chamou consciência fina do seu corpo e do outro.

Nessa leitura fina, temos que realizar um trabalho de aceitar as vulnerabilidades e fragilidades do outro. Temos que aprender a observar esses corpos e compreender o que falam com sua tonicidade, o que expressam pela respiração, o que dizem quando há o relaxamento da musculatura, o que nos escapa pela fuga do olhar e conexões dele, identificar os gestos de recusa e de aceitação e os significados da explosão corporal por trás das crises.

Para Merleau-Ponty (1999, p. 269), quer se trate do corpo do outro ou de meu próprio corpo, não tenho outro meio de conhecer o corpo humano senão vivê-lo. Ou seja, há a necessidade de entrar em contato com o nosso corpo para estarmos em relação no mundo. O sujeito dentro do TEA possui um corpo que sente, que vive e que interage do seu modo, buscando realizar suas experiências corporais das formas que lhe são possíveis. Pensar na inclusão desses corpos é pensar em um espaço relacional de aprendizagem, no qual haja uma relação direta com o mundo, de modo que o corpo seja o território em que se vivenciam todas as aprendizagens motoras, emocionais, sensoriais e racionais. Por meio da exploração do corpo, aprendemos, criamos, recriamos e realizamos movimentos para nos reconhecermos como sujeitos globais.

Falar de espaço, tempo e corpo na escola é falar de ritmo, é entender que ele divide o tempo que é cadenciado por um gesto e por outro, compreendendo-o como regulador do tempo de aprendizagem de cada criança. Lapierre e Aucouturier (1984, p. 51) ressaltam que a maioria dos professores está condicionada pela situação escolar tradicional, em que cada um deve fazer a mesma coisa ao mesmo tempo, participar com os outros da mesma atividade.

O que proponho, nesta discussão, é pensar na criação de um espaço relacional que será construído por meio do conhecimento de si e das relações geográficas com os outros - um lugar comum para todas as crianças, no qual seus espaços individuais 


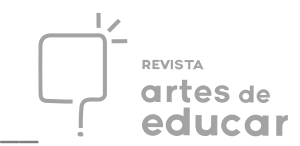

sejam respeitados sem que se percam as relações, a autonomia, o respeito e a solidariedade.

Não permitir que o estudante explore seu corpo, compreendendo seu próprio ritmo, reprimindo o seu movimento dentro de uma racionalidade, do silêncio e da imobilidade têm como consequência um empobrecimento das experiências motoras e do entendimento dele de mundo e da aprendizagem.

Dar voz ao corpo significa abrir a escuta, o pensar, o sentir; é olhar além e perceber o que há por trás das estereotipias, das dificuldades de socialização, da sustentação do olhar, do entendimento das expressões faciais, dos gestos e da comunicação não verbal. É levá-lo a reconhecer e despertar as suas noções espaciais e temporais, para que possa realizar expressões verbais e gestuais, de modo a perceber seu corpo como um continente, como território de trocas com outros continentes, como ressalta Bertazzo (2018, p.138).

Precisamos encontrar, dentro da escola, uma sintonia entre o corpo e a mente, a fim de que tenhamos um espaço para a experiência de uma educação aberta para a vida, no qual essas crianças sejam vistas e tratadas como seres globais - afetivos, psicomotores, cognitivos e espirituais. Assim, será possível fazer o exercício de perceber cada sujeito nas suas singularidades, complexidades, possibilidades e impossibilidades. Precisamos construir um lugar onde vivenciemos, nos corpos, as experiências, como aquilo que "nos passa, o que nos acontece, o que nos toca", como afirma Larrosa (2015, p. 18), dando espaço e tempo para as relações que realmente importam para a construção de saberes. Nesse ambiente, poderemos deixar um pouco de lado as informações, as opiniões e a falta de tempo e daremos vazão ao acontecimento, tornando-nos sujeitos da experiência.

\section{O pequeno super-herói}

Atuando no Centro de Referência, chego a atender em torno de 80 usuários com deficiências diversas. Dentre tantos, gostaria de apresentar um caso - um menino que chegou a mim com 13 anos, 1,90m, cerca de 100kg e um diagnóstico de autismo. Esse adolescente, chamado Usuário $\mathrm{X}^{4}$, já havia passado por diversas terapias, e sua falta de 
concentração e desorganização corporal sempre foram questões para um maior desenvolvimento.

Usuário X era grande - seu tamanho, por si só, já assustava e eram frequentes as crises nervosas. Além disso, ele era totalmente enlouquecido pelo mundo dos superheróis. A todo tempo, ele se imaginava como sendo um herói diferente: tinha poderes, lutava contra o vento, recuperava tesouros e salvava amigos imaginários.

Ao entrar pela primeira vez na minha sala, abriu a porta como se estivesse arrombando com os ombros, olhou para mim e, com as mãos, me acertou com uma chuva de lasers imaginários. Eu, rapidamente, me joguei no chão e busquei ir à sua direção me rastejando. Ele, percebendo minha aproximação, se esquivou para o canto da sala, estabelecendo um limite claro entre nossos espaços. Na mesma hora, recuei. Cabe trazer as palavras de Viana (2015, p. 57): o fator que deve delimitar nosso movimento em direção a uma pessoa é a reação que ela tem de recusa ou aceitação, de incômodo ou prazer.

Durante muito tempo, observei o Usuário X. Ele falava ao vento, o que, para alguns profissionais, soava como um traço de uma possível psicose. Entretanto, parando para reparar um pouco mais detalhadamente nos seus gestos miúdos e nas palavras que balbuciava, logo víamos que estava brincando constantemente de super-herói. Para ter acesso ao Usuário X, era necessário entender o espaço que ele havia criado ao seu redor.

Passei, aos poucos, a transformar nosso espaço de trabalho, trazendo objetos com os quais Usuário $\mathrm{X}$ pudesse se relacionar e que aguçassem a sua criatividade ao brincar, como os flutuadores de piscinas em formato de espaguete, que viraram espadas, lanças e escudos. Tecidos viraram grandes capas. Cordas serviam para se defender, prender e atacar os inimigos. Gradativamente, trouxe a música para o nosso espaço, de modo que Usuário X identificava todas as trilhas de super-heróis. Depois, os colchões forravam o chão para que o adolescente pudesse explorá-lo. A cada encontro, eu fazia novos convites a ele ao trazer novos objetos para transformar e explorar o espaço, no qual pudesse experimentar diversas formas de usar seu corpo e possibilidades variadas de vivenciar novas experiências.

Para Lapierre e Aucouturier (1986, p. 39): 
É a descoberta de um poder sobre os objetos, sobre o mundo, sobre o outro, poder que se exerce por intermédio de um poder sobre seu corpo. A descoberta desse poder agir, associado ao poder sentir, vai trazer uma nova dimensão ao prazer primitivo do movimento. É prazer de ação, o prazer de pegar o objeto, de dar-lhe movimento, de deslocá-lo, de lançá-lo, de modificar sua forma, de fazer barulho com ele.

Progressivamente, Usuário X me convidou para brincar, para entrar no seu espaço. Ao mesmo tempo, passei a provocar a dança, uma dança de super-heróis, na qual voávamos, chutávamos, corríamos, rolávamos, pulávamos - sempre com cuidado, atenção, respeito e escuta, lembrando que estávamos construindo uma relação pelo corpo.

Esse menino foi perdendo os receios, rompendo as barreiras, ampliando seu espaço, permitindo o toque, se deixando expor, se movimentar, se propor a novas experiências corporais. Ele foi se permitindo pisar em terreno desconhecido, uma vez que tínhamos um espaço acolhedor e de afeto no qual se sentia seguro. Esse despertar do corpo trouxe-lhe a vontade de se movimentar com o outro, de estar com o outro, de aprender com o outro.

O trabalho com o Usuário $\mathrm{X}$, como com outros que participam da oficina de dança, não é pensar formas de se trabalhar a estética do corpo e do movimento, mas de encontrar o entendimento desse corpo, entender a sua funcionalidade, a sua expressão e ter a disposição para assumir os seus corpos com suas deficiências.

O Usuário X precisava trabalhar seu tônus, e fomos aprofundando esse trabalho com o toque, pois passamos do trabalho da relação tátil com os objetos, modelando e experimentando diversos materiais, com tipos de texturas diversas, passando por aprofundar lentamente o toque no seu próprio corpo, chegando por fim a possibilidade de poder tocar o outro.

Nesse momento, então, passamos a descobrir juntos esses toques, a força aplicada, a sutileza, o carinho, o vigor, a troca de peso, o equilíbrio, passamos a estudar e entender o tocar com qualidade. Desenvolvemos juntos não apenas uma escuta sensível, mas um toque sensível para perceber as sutilezas do nosso corpo, do espaço que ocupamos e a do mundo e, assim, foi construído um corpo mais relaxado e um 
tônus menos tenso, daqueles que eram presentes nas brincadeiras de super-herói. $\mathrm{O}$ Usuário X passou a entender seu corpo no espaço de outra forma.

Esse percurso que traçamos permitiu aos poucos que esse jovem começasse a sentar nas terapias, a realizar atividades mais focadas, entendendo melhor seu tônus, compreendendo seu eixo de equilíbrio e regulando sua força. Diminuindo suas crises nervosas, com a regulação corporal, passou a ter maior atenção, começou a se interessar pelo convívio com o outro, passou a dançar com outras músicas e com outros da sua idade. Usuário $\mathrm{X}$ foi construindo no seu corpo sua relação com o mundo, o que, nas palavras de Larrosa (2015, p. 25) é como um território de passagem, algo como uma superfície sensível que aquilo que acontece afeta de algum modo, produz alguns afetos, inscreve algumas marcas, deixa alguns vestígios, alguns efeitos.

Nesse espaço de encontro que construímos, o tempo era nosso e, devido a isso, fomos nos permitindo perceber e sentir um ao outro, para, depois, agirmos. Existem diversas formas de nos colocarmos em relação, basta que tenhamos uma sensibilidade fina para torná-la possível. Precisamos pensar em formas de criar na escola um espaço 'de' e 'para' a relação, de criação, para a inclusão, com tempo, no qual possamos interagir com o meio e com o outro, influenciando e sendo influenciado para o nosso desenvolvimento como sujeitos.

\section{Considerações finais}

Ao escrever este trabalho, não falo do lugar de um especialista sobre inclusão escolar. Gostaria, antes, de realizar um convite para pensarmos e falarmos sobre a construção do espaço das pessoas com TEA dentro desse ambiente, ressaltando a importância da experiência de mundo pelo corpo. Entendo essas experiências numa perspectiva única, como nos aponta Larrosa, pois são individuais e não são percebidas da mesma forma, exigindo outro tempo e espaço para que se tornem possíveis suas vivências.

É necessário pensar os corpos dentro do transtorno do espectro autista como diferentes entre si, pois cada qual tem suas especificidades. Os sinais do autismo podem ser entendidos como possíveis movimentos criadores, não como incapacidade. A 
aceitação da condição da forma de ser e habitar desses corpos no mundo é algo primordial para o estabelecimento de um espaço relacional, em que possam ser vistos como sujeitos globais.

É preciso entender, do encontro com a experiência, uma possibilidade de acontecimento no espaço escolar, no qual a troca constrói uma relação individual e com o próximo e exige um tempo diferente, que se permite demorar, que requer atenção e uma delicadeza que perceba, nos pequenos sinais, uma construção e uma reconstrução da aprendizagem.

Ao dançar com pessoas dentro do espectro autista, pude entender esse espaço relacional que exige uma suspensão do tempo para que se possa viver a experiência, sentir, tocar, escutar, para perceber os espaços e as relações que podemos realizar, de modo que os envolvidos se construam e se reconstruam em um exercício constante mediado pelo movimento. Cada encontro abre espaços diferentes, com novas relações e potencialidades a serem percebidas e exploradas. Esses locais é que darão origem à experiência que permitirá que esses ritmos demonstrem modos diferentes de caminhar e estar no mundo e caminhos diversos para construir o conhecimento.

Todos nós somos espaço, estamos no espaço, vivemos o espaço e nossos corpos se ligam e aprendem por meio desse espaço-tempo. Não devemos nos prender a lugares de ordem, mas devemos nos permitir explorar ao máximo formas de nos envolver, de perceber e de ser no mundo a partir de experiências únicas.

Nesse aspecto, minhas vivências com o espaço não são apenas terapêuticas, mas são um território para o acontecimento, que permite a criação, a recriação, as descobertas e os encontros, de modo que, segundo Viana e Castilho (2002, p. 24), "saber olhar esses corpos com a peculiaridade de cada um é o fundamento de uma didática do cuidado". Este é o cuidado que devemos ter conosco e com o outro para que se torne possível o surgimento de um lugar em que se possa viver a experiência de ser e estar no mundo dentro de um espaço relacional, no qual os envolvidos tenham liberdade para serem permeáveis, transpassados e afetados pela troca - características essenciais para a escola. 


\section{REFERENCIAS}

AMERICAN PSYCHIATRIC ASSOCIATION - APA. Manual diagnóstico e estatístico de transtornos mentais: DSM5. 5. ed. Porto Alegre: Artmed, 2014.

BERTAZZO, Ivaldo. Fases da vida. Gestão à puberdade. São Paulo: Edição Sesc, 2018.

BRASIL. Constituição da República Federativa do Brasil de 1988. Brasília: Presidência da República, 1988. Disponível em:

http://www.planalto.gov.br/ccivil_03/constituicao/constituicao.htm. Acesso em: 29 jul. 2019.

BRASIL. Lei $\mathbf{n}^{\mathbf{0}}$ 4.024, de 20 de dezembro de 1961. Fixa as diretrizes e bases da Educação Nacional. Brasília: Presidência da República, 1961. Disponível em: http://www.planalto.gov.br/ccivil_03/leis/L4024.htm. Acesso em: 29 jul. 2019.

BRASIL. Lei $\mathrm{n}^{\mathbf{0}}$ 5.692, de 11 de agosto de 1971. Fixa diretrizes e bases para o ensino de $1^{\circ}$ e $2^{\circ}$ graus, e dá outras providências. Brasília: Presidência da República, 1971. Disponível em: http://www.planalto.gov.br/ccivil_03/leis/L5692.htm. Acesso em: 29 jul. 2019.

BRASIL. Lei no 9.394, de 20 de dezembro de 1996. Fixa diretrizes e bases da educação nacional. Brasília: Presidência da República, 1996. Disponível em: http://www.planalto.gov.br/ccivil_03/Leis/L9394.htm. Acesso em: 03 ago. 2019.

BRASIL. Lei n 12.394, de 27 de dezembro de 2012. Institui a Política Nacional de Proteção dos Direitos da Pessoa com Transtorno do Espectro Autista; e altera o $\S 3^{\circ}$ do art. 98 da Lei $\mathrm{n}^{\circ}$ 8.112, de 11 de dezembro de 1990. Brasília: Presidência da República, 2012. Disponível em: http://www.planalto.gov.br/ccivil_03/_Ato20112014/2012/Lei/L12764.htm. Acesso em: 03 ago. 2019.

BRASIL. Lei n⿳ 13.005, de 25 de junho de 2014. Aprova o Plano Nacional de Educação - PNE e dá outras providências. Brasília: Presidência da República, 2014. Disponível em: http://pne.mec.gov.br/18-planos-subnacionais-de-educacao/543-planonacional-de-educacao-lei-n-13-005-2014. Acesso em: 04 ago. 2019.

BRASIL. Lei $\mathbf{n}^{\mathbf{0}}$ 13.146, de 6 de julho de 2015. Institui a Lei Brasileira de Inclusão da Pessoa com Deficiência (Estatuto da Pessoa com Deficiência). Brasília: Presidência da República, 2015. Disponível em: http://www.planalto.gov.br/ccivil_03/_ato20152018/2015/lei/113146.htm. Acesso em: 05 ago. 2019.

DONVAN, John; ZUCKER, Caren. Outras Sintonias. A história do autismo.Tradução de Luiz A. de Araujo. São Paulo: Companhia das Letras, 2017.

FOUCAULT, Michel. Vigiar e punir: nascimento da prisão. Tradução de Raquel Ramalhete. Petrópolis: Vozes, 1987. 
FRAGA, A. B. Anatomias emergentes e o bug muscular: pedagogias do corpo no limiar do século XXI. In: SOARES, Carmen Lúcia (Org.). Corpo e história. $3^{\text {a }}$ ed. Campinas: Autores Associados, 2006.

GIKOVATE, Carla.Autismo: compreendendo para melhor incluir. Rio de Janeiro, 2009. Disponível em: https://docplayer.com.br/164060-Carla-gruber-gikovate-autismocompreendendo-para-melhor-incluir.html. Acesso em:17 ago. 2019.

LAPIERRE, André; AUCOUTURIER, Bernard. Fantasmas corporais e prática psicomotora. São Paulo: Ed. Manole, 1984.

A simbologia do movimento: psicomotricidade e relação. Tradução de Márcia Lewis. Porto Alegre: Artes Médicas, 1986.

LAPIERRE, André; LAPIERRE, Anne. $O$ adulto diante da criança de 0 a 3 anos:psicomotricidade relacional e formação da personalidade. Curitiba: UFPR/CIAR, 2002.

LARROSA, Jorge. Tremores: escritos sobre experiência. Coleção Experiência e Sentido.Belo Horizonte: Autêntica, 2015.

LE BOULCH, Jean. O desenvolvimento psicomotor: do nascimento até os 6 anos. Porto Alegre: Artes Médica, 2001.

LE BRETON, David. A sociologia do corpo. $2^{a}$ ed. Tradução de Sônia M.S. Fuhrmann. Petrópolis: Vozes, 2007.

MERLEAU-PONTY, M. Fenomenologia da percepção. Tradução de Carlos Alberto Ribeiro de Moura. São Paulo: Martins Fontes, 1999.

UNESCO. Declaração de Salamanca: sobre princípios, políticas e práticas na área das necessidades educativas especiais. Salamanca, 1994. Disponível em: http://portal.mec.gov.br/seesp/arquivos/pdf/salamanca.pdf. Acesso em: 10 ago. 2019.

VIANA, Anamaria Fernandes. Dança e autismo, espaços de encontro. 2015. 436 p. Tese (Doutorado). Faculdade de Educação, Universidade Estadual de Campinas, Campinas, 2015. Disponível em:

http://www.repositorio.unicamp.br/handle/REPOSIP/253990. Acesso em: 10 ago. 2019.

VIANNA, Angel; CASTILHO, Jacyan. Percebendo o corpo. In: GARCIA, Regina Leite. $O$ corpo que fala dentro e fora da escola. Rio de Janeiro: DP\&A, 2002. 
${ }^{\mathrm{i}}$ Mestre em Artes Cênicas, Bacharel em Artes Cênicas e Licenciado em Pedagogia pela Universidade Federal do Estado do Rio de Janeiro - UNIRIO. Psicomotricista Educacional pela Universidade do Estado do Rio de Janeiro - UERJ. Formado no Método Bertazzo. Atualmente Educador em Dança da Secretaria Municipal da Pessoa com Deficiência e Tecnologia do Rio de Janeiro. https://orcid.org/00000002-3094-7698 /Email: renatodesena@gmail.com

${ }^{2}$ No Manual Diagnóstico e Estatístico de Transtornos Mentais (DSM-IV), o Transtorno Autista, como outros transtornos, era classificado como Transtornos Globais do Desenvolvimento (TGD). Com a intenção de facilitar o diagnóstico, houve a implementação do DSM-5: o Transtorno Autístico (Autismo), o Transtorno de Asperger, o Transtorno Desintegrativo da Infância e o Transtorno Global ou Invasivo do Desenvolvimento passaram a pertencer à categoria denominada Transtornos de Neurodesenvolvimento, classificada como Transtornos do Espectro Autista (TEA).

${ }^{3}$ Dado correspondente ao quantitativo de setembro de 2019.

${ }^{4} \mathrm{O}$ nome foi substituído por Usuário $X$ com a intenção de preservar a identidade dele. 